\title{
Antiproliferative Effect of Androgen Receptor Inhibition in Mesenchymal Stem-Like Triple-Negative Breast Cancer
}

\author{
Aiyu Zhu ${ }^{\mathrm{a}}$ Yan Li ${ }^{\mathrm{a}}$ Wei Song ${ }^{\mathrm{a}}$ Yumei Xu Fang Yang $^{\mathrm{b}}$ Wenwen Zhang ${ }^{\mathrm{b}}$ \\ Yongmei Yinc Xiaoxiang Guana,b \\ aDepartment of Medical Oncology, Jinling Hospital, Southern Medical University, Guangzhou, \\ bDepartment of Medical Oncology, Jinling Hospital, Medical School of Nanjing University, Nanjing, \\ 'Department of Oncology, The First Affiliated Hospital of Nanjing Medical University, Nanjing, China
}

\section{Key Words}

Androgen receptor • Triple-negative breast cancer • p53 • p73 • p21

\begin{abstract}
Background/Aims: Androgen receptor (AR), a steroid hormone receptor, has recently emerged as prognostic and treatment-predictive marker in breast cancer. Previous studies have shown that $A R$ is widely expressed in up to one-third of triple-negative breast cancer (TNBC). However, the role of AR in TNBC is still not fully understood, especially in mesenchymal stemlike (MSL) TNBC cells. Methods: MSL TNBC MDA-MB-231 and Hs578T breast cancer cells were exposed to various concentration of agonist 5 - $\alpha$-dihydrotestosterone (DHT) or nonsteroidal antagonist bicalutamide or untreated. The effects of AR on cell viability and apoptosis were determined by MTT assay, cell counting, flow cytometry analysis and protein expression of p53, p73, p21 and Cyclin D1 were analyzed by western blotting. The bindings of AR to p73 and p21 promoter were detected by ChIP assay. MDA-MB-231 cells were transplanted into nude mice and the tumor growth curves were determined and expression of AR, p73 and p21 were detected by Immunohistochemistry (IHC) staining after treatment of DHT or bicalutamide. Results: We demonstrate that AR agonist DHT induces MSL TNBC breast cancer cells proliferation and inhibits apoptosis in vitro. Similarly, activated AR significantly increases viability of MDA-MB-231 xenografts in vivo. On the contrary, AR antagonist, bicalutamide, causes apoptosis and exerts inhibitory effects on the growth of breast cancer. Moreover, DHTdependent activation of AR involves regulation in the cell cycle related genes, including p73, p21 and Cyclin D1. Further investigations indicate the modulation of AR on p73 and p21 mediated by direct binding of AR to their promoters, and DHT could make these binding more effectively. Conclusions: Our study demonstrates the tumorigenesis role of AR and the inhibitory effect of bicalutamide in AR-positive MSL TNBC both in vitro and in vivo, suggesting that AR inhibition could be a potential therapeutic approach for AR-positive TNBC patients.

A. Zhu and Y. Li contributed equally to the work.




\section{Cellular Physiology Cell Physiol Biochem 2016;38:1003-1014 \begin{tabular}{l|l} 
and Biochemistry Published online: March 04, 2016 & $\begin{array}{l}\text { DOI: } 2016 \text { The Author(s). Published by S. Karger AG, Basel } \\
\text { www.karger.com/cpb }\end{array}$
\end{tabular} \\ Zhu et al.: Targeting Androgen Receptor in Triple-Negative Breast Cancer}

\section{Introduction}

Triple-negative breast cancer (TNBC) makes up about 10 to $20 \%$ of invasive breast cancers, which has lowest 5-year survival rate and worst overall survival compared with other breast cancer subtypes [1]. Previous studies demonstrated that TNBC tumors are associated with larger size, higher grade and lymph node involvement at diagnosis, which display more aggressive clinical course [2]. As it lacks estrogen receptor (ER) and progesterone receptor (PR) expression as well as human epithelial receptor-2 (HER-2) amplification, treatments targeting ER or HER-2 are not effective. Up to now, there is no optimal standard of care for the management of TNBC. Although TNBC is defined by its lack of the hormone receptors traditionally associated with breast cancer, it expresses other hormone receptors like the glucocorticoid receptor and androgen receptor (AR) [3]. AR, also belongs to nuclear hormone receptor family, interacts with molecules in the nuclear [4], which is widely expressed in up to one-third of TNBC [5-8]. Lehmann and colleagues proposed seven subtypes of TNBC, including basal-like 1, basal-like 2, mesenchymal-like, mesenchymal stem-like (MSL), immunomodulatory, luminal AR (LAR) and unclassified TNBC. In recent studies, AR functions as an anti-tumor effecter in ER-positive breast cancer by antagonizing ER [9], whereas it promotes tumor cell growth in TNBC, as AR inhibition bicalutamide reduces cancer cell viability and proliferation in multiple molecular subtypes of TNBC cells both in vitro and in vivo, including MSL TNBC cells [10]. It has been well demonstrated that androgen induces LAR subtype breast cells proliferation in previous studies. Thus, MSL TNBC breast cancer cells MDA-MB-231 and Hs578T are also sensitive to AR inhibition, though express lower level of AR than LAR cell lines.

Previous clinical studies have designed to study the effectiveness of androgen blockade in breast cancer. A phase II trial in patients with ER-/PR-/AR+ metastatic breast cancer has shown a clinical benefit rate of $19 \%$ for bicalutamide [11]. Another phase II study assessing the safety of enzalutamide in AR-positive TNBC or advanced breast cancer is ongoing (NCT01889238). Moreover, a recent case report showed that a 55-year old woman with AR-positive metastatic TNBC received clinical response after 4 months treatment of oral bicalutamide $150 \mathrm{mg}$ every day [12].

Previous study has demonstrated that MDA-MB-231 and Hs578T belong to MSL TNBC cells, which are sensitive to AR inhibition bicalutamide [10]. In our study, we designed to investigate whether bicalutamide inhibits TNBC proliferation involves the regulation of cell cycle related genes, including tumor suppressors p53, p73, cyclin-dependent kinase p21 (CIP1/WAF1), and Cyclin D1. Ligand-activated AR regulates the cell cycle has been generally defined in prostate cancer, and AR down-regulation induces cell cycle arrest and accumulation of the p27 cyclin-dependent kinase inhibitor demonstrated in previous study [13]. In addition, androgen stimulation elevates in Cyclin D proteins, resulting in activation of CDK4/6 and causes proliferation in prostate cancer cells [14]. However, the functional role of AR on breast cancer development and progression remains largely unclear. Thus, in our study, we designed to investigate the effect of AR in breast cancer growth and the link between AR and cell cycle related genes in MSL TNBC using in vitro and in vivo models. Further, we also wish to examine the efficacy of AR inhibition bicalutamide as a targeted therapy in AR-positive MSL TNBC.

\section{Materials and Methods}

\section{Cell culture and treatment}

TNBC cell lines MDA-MB-231 and Hs578T were obtained from the American Type Culture Collection (Manassas, VA, USA). MDA-MB-231 cell line was cultured in RPMI 1640 medium (GIBCO, Gaithersburg, MD, USA) supplemented with 10\% fetal bovine serum (FBS) and 1\% penicillin/streptomycin. Hs578T cell line was cultured in DMEM medium (GIBCO, Gaithersburg, MD, USA) with 10\% FBS, 1\% penicillin/ streptomycin and $5 \%$ insulin. Cell cultures were carried out in a humiditied $37^{\circ} \mathrm{C}$ incubator supplied with 


\section{Cellular Physiology Cell Physiol Biochem 2016;38:1003-1014

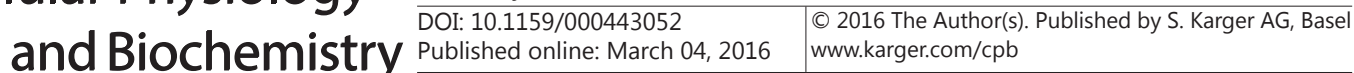 \\ Zhu et al.: Targeting Androgen Receptor in Triple-Negative Breast Cancer}

$5 \% \mathrm{CO}_{2}$. Dihydrotestosterone (DHT) (Sigma) was dissolved in ethanol at 0.1 to $100 \mathrm{nM}$ concentration, and bicalutamide (Sigma) were dissolved in dimethylsulfoxide (DMSO, Sigma) at 0.1 to $10 \mu \mathrm{M}$ concentration.

\section{Cell viability/proliferation assay}

MDA-MB-231 (6,000 cells/well) and Hs578T (10,000 cells/well) were seeded in 96-well tissue culture dishes. After $24 \mathrm{~h}$, cells were exposed for 3 days to various concentration of DHT or bicalutamide or untreated. Cell viability was assessed using the method of Methylthiazolyldiphenyl-tetrazolium bromide assay. Cells were incubated with various treatments for 24, 48 and $72 \mathrm{~h} .10 \mu \mathrm{l}$ of $0.5 \mathrm{mg} / \mathrm{ml}$ MTT solution (Sigma) were added to each well, and the plates were incubated for $4 \mathrm{~h}$ at $37^{\circ} \mathrm{C}$. After $4 \mathrm{~h}$ the medium was replaced with $150 \mu \mathrm{L}$ DMSO. The absorbance was measured with $490 \mathrm{~nm}$ with a microplate reader (BIORAD, USA). Each assay was performed in triplicate. In the same experimental condition, MDA-MB-231 and Hs578T were planted on 24-well tissue culture dishes $\left(2 \times 10^{4}\right.$ cells/well). MDA-MB-231 cells were exposed for 3 days to 10nM DHT, $1 \mu \mathrm{M}$ bicalutamide or untreated and Hs578T cells exposed to $100 \mathrm{nM}$ DHT, $10 \mu \mathrm{M}$ bicalutamide or untreated. At the above indicated time points, the effects of the various treatments on cell proliferation were measured by counting MDA-MB-231 and Hs578T cells using a Burker's chamber, with cell viability determined by trypan blue dye exclusion.

\section{Apoptosis analysis}

An annexin V-florescein isothiocyanate (FITC) apoptosis detection kit (KeyGEN Biotech, CA) was used to detect apoptosis according to the manufacturer's instructions. MDA-MB-231 and Hs578T cells were planted on six-well plates $\left(10^{5}\right.$ cells/well). After $24 \mathrm{~h}$, cells were exposed to $100 \mathrm{nM}$ DHT or $10 \mu \mathrm{M}$ bicalutamide or under ethanol/DMSO (vehicle control) treated condition. The rate of early apoptosis was monitored with a flow cytometer (BD FACS calibur, USA). Each sample was tested in triplicate.

\section{Western blot analysis}

Whole-cell protein was extracted using RIPA buffer supplemented with protease and phosphatase inhibitors and quantified using BCA kit (Thermo Scientifi). $20 \mu$ g protein were denatured, separated on SDS-PAGE gels, and transferred to polyvinylidene fluoride membranes. Blots were blocked with 5\% dry milk in tris-buffered saline $/ 0.1 \%$ tween-20 and incubated overnight with a diluted solution of primary antibody at $4^{\circ} \mathrm{C}$, and then with the horseradish peroxidase-conjugated secondary antibody (1:5000) for $2 \mathrm{~h}$. Primary antibodies used included: AR (ab74272, 1:200, Abcam), p73 (ab17230, 1:300, Abcam), p53 (ab32049, 1:500, Abcam), Cyclin D1 (\#2926, 1:2000, Cell Signaling Technology), p21 (\#2946, 1:2000, Cell Signaling Technology). Bands were normalized to GAPDH expression which was used as an internal loading control. Results from at least two separate experiments were analyzed.

\section{Immunohistochemistry staining}

Slides were deparaffinized in a series of xylenes and ethanols. Heat-mediated antigen retrieval was fulfilled with citrate buffer (BioGenex Laboratories, San Ramon, CA). Antibodies used were AR (ab74272, 1:100, Abcam), p73 (ab17230, 1:100, Abcam), p21 (\#2946, 1:30, Cell Signaling Technology). Immunostained sections were scanned using a microscope at $\times 400$ magnification (Carl Zeiss, Germany). The total number of AR, p73 and p21 positive cells in a tumor cross-section was counted to measure in each sample.

\section{ChIP assay}

The ChIP assay was performed using Pierce Agarose ChIP Kit (Thermo). Briefly, 70\% confluent MDAMB-231 cells were treated with ethanol or $10^{-7} \mathrm{~mol} / \mathrm{L}$ DHT for $2 \mathrm{~h}$ and then fixed in $1 \%$ formaldehyde for $15 \mathrm{~min}$. Centrifugation for $5 \mathrm{~min}$, and sonicate the lysate to shear the cross-linked DNA to an average length of 100-1000 bp. Remove the insoluble material by centrifugation. The immuno-cleared chromatin was immunoprecipitated with anti-AR (Ab74272, abcam) or control IgG antibody overnight at $4^{\circ} \mathrm{C}$. Reverse the cross-links by proteinase K in ChIP Elution buffer for $1.5 \mathrm{~h}$ at $65^{\circ} \mathrm{C} .1 \mu \mathrm{l}$ of each of the purified DNA was used to determine the concentration. Each sample was used as template for PCR with specific primers. 9 and 10 primer sets were designed for the p73 and p21 promoter region respectively. Primer sequences were designed for every $300 \mathrm{bp}$ of each promoter set shown in Table 1, as the sequences amplified by primer sets 1 is the fastest from the transcription start site. PCR analysis was performed in a $20 \mathrm{uL}$ volume with amplifiation conditions: $95^{\circ} \mathrm{C}$ for $5 \mathrm{~min}$; 35 cycles of $95^{\circ} \mathrm{C}$ for $30 \mathrm{~s}, 60^{\circ} \mathrm{C}$ for $30 \mathrm{~s}$, and $72^{\circ} \mathrm{C}$ for $30 \mathrm{~s} ; 72^{\circ} \mathrm{C}$ for $10 \mathrm{~min}$. PCR products were separated on $2 \%$ agarose gels, stained with ethidium bromide and photo each. 


\section{Cellular Physiology Cell Physiol Biochem 2016;38:1003-1014 \begin{tabular}{l|l} 
and Biochemistry & DOI: 10.1159/000443052 \\
Published online: March 04, 2016 2016 The Author(s). Published by S. Karger AG, Basel \\
www.karger.com/cpb
\end{tabular} \\ Zhu et al.: Targeting Androgen Receptor in Triple-Negative Breast Cancer}

Table 1. PCR sequences of primer sets designed for p73 and p21 promoter in ChIP analysis. 9 and 10 primer sets were designed for the p73 and p21 promoter region respectively. Primer sequences were designed for every $300 \mathrm{bp}$ of each promoter. The sequences amplified by primer sets 1 is the fastest from the transcription start site

\begin{tabular}{cccc}
\hline & p73 & & p21 \\
No. & Sequences (5' to 3') & No. & Sequences (5' to 3') \\
\hline 1 & GCGGCCGCCCCCGGCCCTGCCCGCC and CGCGGAAGTCGGCGGCGCTGATAGG & 1 & TGCCTGTAATCCCAGCTACTCGGGA and GACTCGCCCCACCCAATGTTTGTAT \\
2 & GCGGCATTGTGGGGCTTGTAGTTCT and ACACACACGCAGACACACAGGTCGC & 2 & TCATCGTCTGACGTCTGGCCGTGAG and TCCTGTTCGTCGATTCTGGCTGCCT \\
3 & TACACATGCATATATATATATTTAT and CGGGCGGTGGCCGCGATCCACGCGC & 3 & AAAACTGGCAGGAAGGCAAAGAAAA and TCTGGTTGGCATCATCTCGCTGGCT \\
4 & GTTCATCACCCGCGCGCATCTGGGC and AGCTCCCAGAACCCAGGGCCAGGCG & 4 & TTTGCCGAAATTATTGAGAAGAATC and GGCTGAGCATATAGTTGTAGCTCCT \\
5 & TGAGAGCCGGCCAGGGTCCTGCTCG and GCCGGGCTGGCGCAGACTGGGTTCT & 5 & CATTGTGTCTGCTGCAAATCTCAGT and TTCCAGAGCCAGGATGAATTGGTAA \\
6 & TCGCTCGCGAAGCCACGGGCTTCAC and GCGCGCACCAGACCTGCGCTAGGTC & 6 & ACAAGCTCTTCGAGGCCAGCATTGA and TGACTGAAACGAAGTAAGAACTCTA \\
7 & AGAGAACAACTCCAAGCGCACCGAC and AGGCCCAGGAGGAGGGGAACGGCTG & 7 & AAGACAATGCTTAGTTCAGATACTC and GCTGAGGTGGGAGAATCGCTTGAAC \\
8 & CTGGGGCGGCGCCCCTCACCCCTGT and CCCACGCAGGGCCGAAGCAGGTCCG & 8 & CACCTGAATACCTGGGACTACAGGT and TTGTATTTTTTTTTTTGCACAAAAA \\
9 & CGGCCTCGCCGGGCTCTGCAGGAGC and CGCCCGGAGGCTCGCGCGCCCGCGA & 9 & AAAAAATACAAATATTAGCTGGGCA and AGTCCCAAATAGGGGCAGTCAGCTT \\
& & 10 & TCCCCAGTCTCTTTCTGAGAAATGG and GGACATGTTCCTGACGGCCAGAAAG \\
\hline
\end{tabular}

Mouse xenograft assay

Six-week-old female BALB/c mice were used for xenograft studies. A total of $5 \times 10^{6}$ MDA-MB-231 cells were injected into flank of each mouse to generate the xenograft tumors. The tumor volumes were determined 3 times per week by measuring the length (l) and width (w) and calculating the tumor volume as $\Pi / 6 \times 1 \times w \times(l+w) / 2$. The mice bearing tumors reached $100 \mathrm{~mm}^{3}$ were randomly grouped and treated by intraperitoneal injection 3 times per week for 4 weeks with DHT $(7 \mathrm{mg} / \mathrm{kg})$ or bicalutamide $(30 \mathrm{mg} /$ $\mathrm{kg}$ ) or untreated. Xenograft tumors were harvested 4 weeks following initial treatments. Fold change in tumor volume was calculated as [volume on treatment week $n(n=1,2,3,4)$ /volume on treatment day 1]. Harvested tumors were fixed in formalin and embedded in paraffin for immunohistochemistry (IHC) staining.

Statistical analysis

Statistical significance was evaluated using one-way ANOVA or student's $t$ test with SPSS Statistics 19.0 (SPSS Inc.). The Mann-Whitney U test was applied for the comparison of nonparametric data. ${ }^{*} P<0.05$ or ${ }^{* *} P<0.01$ were considered statistical significant.

\section{Results}

AR is expressed in MSL TNBC

Previous study has demonstrated that LAR TNBC expresses high levels of AR. Compared with LAR, MSL TNBC expresses relative lower level of AR. However, treatment with AR agonist DHT and antagonist bicalutamide altered expression of AR in this subtype of TNBC. In MDA-MB-231 and Hs578T cell lines, treatment with DHT significantly increased protein level of AR, whereas bicalutamide, which completely binds to AR and increases AR degradation, inhibited this effect (Fig. 1), which indicated that AR agonist DHT and antagonist bicalutamide are effective in MDA-MB-231 and Hs578T cell lines.

AR inhibition reduces MSL TNBC cell viability and increases apoptosis in AR-positive TNBC

To further investigate the effects of AR agonist DHT and antagonist bicalutamide on cell viability, we assessed the effects of increasing concentrations of DHT at 0.1 to $100 \mathrm{nM}$ and bicalutamide at 0.1 to $10 \mu \mathrm{M}$ on TNBC cells (MDA-MB-231, Hs578T). MDA-MB-231 cells proliferation effectively increased after $72 \mathrm{~h}$ of DHT treatment, while bicalutamide appeared to exert inhibitory effects on cellular proliferation, which was observed in dose-dependent manner (Fig. 2A). These observations can be reduplicated in the Hs578T breast cancer cell line, as bicalutamide decreased cell proliferation of Hs578T and cell proliferation significantly induced in Hs578T at the highest concentration of $100 \mathrm{nM}$ after $72 \mathrm{~h}$ DHT treatment (Fig. 2B). The effect of AR on cellular proliferation was also assessed by cell counting assay, which was consistent with the MTT assays (Fig. 2C). These data well corrected with apoptosis assay. Early apoptosis rate was decreased after DHT treatment assessed by flow cytometry 


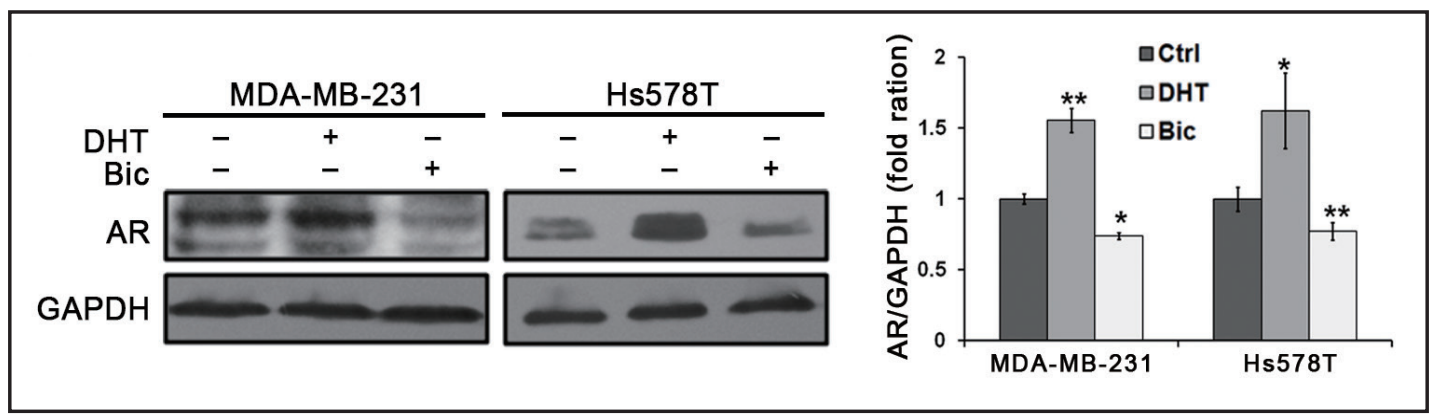

Fig. 1. MDA-MB-231 cells were treated with $10 \mathrm{nM}$ DHT or $1 \mu \mathrm{M}$ bicalutamide or untreated, and Hs578T cells were treated with $100 \mathrm{nM}$ DHT or $10 \mu \mathrm{M}$ bicalutamide or untreated for $48 \mathrm{~h}$. The protein expression levels of AR were determined by western blot. The fold changes in intensity normalized by GAPDH were showed by densitometric analysis.



Fig. 2. Effects of DHT and bicalutamide on the cell viability and apoptosis in MDA-MB-231 and Hs578T. (A) MDA-MB-231 and (B) Hs578T cells were treated with various concentrations of DHT and bicalutamide for different time durations, and cell viability was determined by MTT assay. (C) MDA-MB-231 cells were treated with $10 \mathrm{nM}$ DHT, $1 \mu \mathrm{M}$ bicalutamide or untreated, and Hs578T cells were treated with $100 \mathrm{nM}$ DHT, $10 \mu \mathrm{M}$ bicalutamide or untreated for indicated time. The cell number was determined by cell counting. (D) Cell apoptosis measured by flow cytometry analysis after cells treated by DHT, bicalutamide or untreated in MDA-MB-231 and Hs578T. ${ }^{*} P<0.05,{ }^{* *} P<0.01$.

assays, while bicalutamide significantly caused 2-flod increase in early apoptosis rate in MDA-MB-231 and Hs578T compared with vehicle-treated controls (Fig. 2D).

Taken together, these findings suggested that impairing AR signaling is able to decrease cellular viability and induce early apoptosis in TNBC cells. Conversely, activating AR signaling with DHT led to promote cell growth and decrease early apoptosis rate in vitro. 


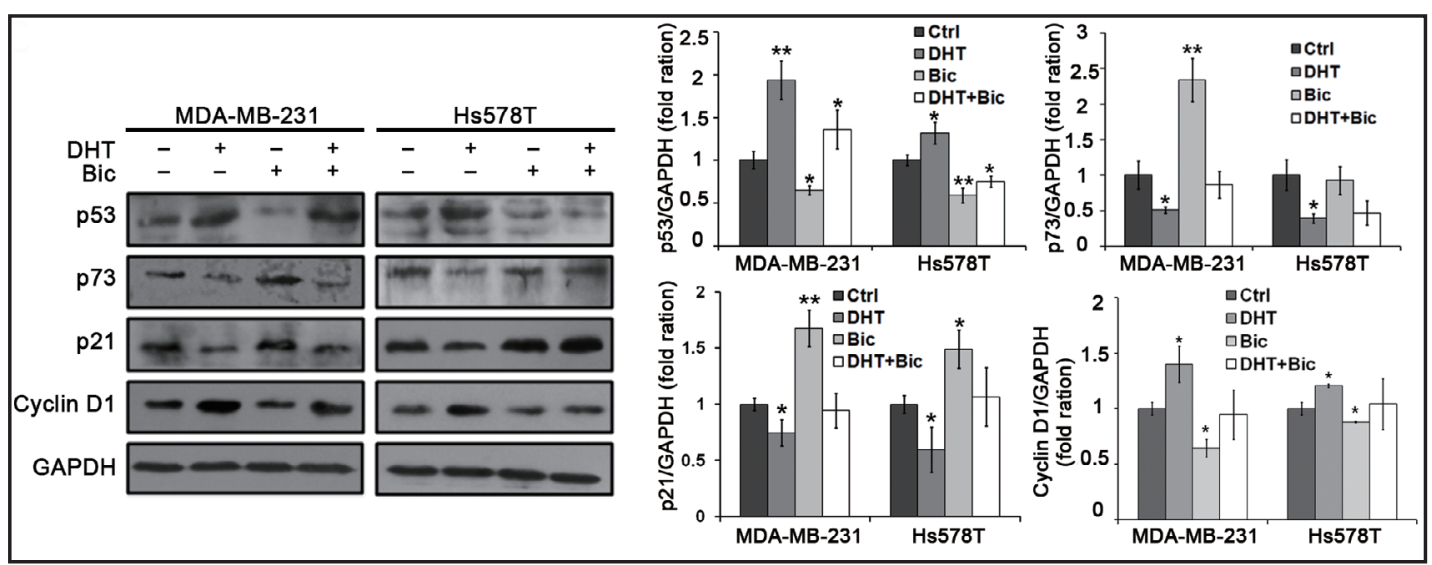

Fig. 3. DHT and bicalutamide regulate the expression of p53, p73, p21, Cyclin D1 in MDA-MB-231 and Hs578T. MDA-MB-231 cells were treated with $10 \mathrm{nM}$ DHT and/or $1 \mu \mathrm{M}$ bicalutamide or untreated, and Hs578T cells were treated with $100 \mathrm{nM}$ DHT and/or $10 \mu \mathrm{M}$ bicalutamide or untreated for $48 \mathrm{~h}$. The protein expression levels of p53, p73, p21, Cyclin D1 were determined by western blot. The fold changes in intensity normalized by GAPDH were shown by densitometric analysis. ${ }^{*} P<0.05$, ${ }^{* *} P<0.01$.

\section{Activated AR regulates expression of cell cycle related genes}

Since DHT increases cellular proliferation in AR-positive TNBC, we assessed whether DHT or bicalutamide effects cell viability consequent to the modulation of cell cycle related genes expression. Therefore, we exposed MDA-MB-231 and Hs578T cells to DHT and bicalutamide for $48 \mathrm{~h}$, and assessed p53, p73, p21, Cyclin D1 protein level by western blot.

We have detected that DHT-activated AR induced the expression of p53, while impairing AR signaling with bicalutamide led to a decrease p53 protein level (Fig. 3). In previous study which suggested that mutant p53 expressed in multiple breast cancer cell lines, including MDA-MB-231 and Hs578T cell lines [15]. As p53 has been revealed as the most frequently mutated gene in breast cancer [15], and mutations in the p53 gene are associated clinically with tumor progression and metastasis [16]. These findings indicate that androgen-activated AR alters expression of p53 may involve the elevation of mutant p53, which leads to the reduction of cell apoptosis. To study the effect of AR on expression of p73 and p21, we exposed MDA-MB-231 and Hs578T to DHT and bicalutamide and assessing p73 and p21 protein levels by western blot. As shown in Fig. 3, the expression of p73 and p21 in protein levels were increased after bicalutamide treatments. Conversely, DHT-activated AR decreased both p73 and p21 protein levels in both cell lines. As shown in our data, Hs578T cells exhibited an increase in the levels of p21 after bicalutamide treatments, but not observed in p73 (Fig. 3).

It is well known that Cyclin D1 expression levels are associated with cancer cell growth and progression [17-19]. Interestingly, activated AR decreases Cyclin D1 expression in MCF7 cell line [20]. Nevertheless, in our study, we observed that DHT induced Cyclin D1 protein levels in AR-positive TNBC cell lines (Fig. 3). Our findings suggested that AR stimulates TNBC cell proliferation may involve altering the expression of p53, p73, p21 and Cyclin D1.

\section{$A R$ regulates the expression of $p 73$ and $p 21$ through binding to their promoters}

To investigate the mechanism of AR induces the proliferation of MSL TNBC cell, we used bioinformatics analysis and ChIP assay to find out whether AR down-regulates the expression of p73 and p21 through binding to their promoters, which results in the proliferation of MSL TNBC cell.

In our study, bioinformatic analysis was used to predict transcription factors binding sites in promoters of target genes, which indicated that both $\mathrm{p} 73$ and $\mathrm{p} 21$ promoters contains putative binding sites for AR. To better determine whether AR binds to the promoters of p73 and p21, we performed ChIP assays in MDA-MB-231. In our results, we found that AR contained the region of p73 and p21 promoters. As shown in Fig. 4A (lane 8), the binding of 
Fig. 4. AR specifially binds to the promoter of p73 and p21 in MDA-MB-231. (A, B) ChIP assay was performed using AR antibody in MDA-MB-231cells. A negative control IgG and input DNA was subjected to PCR amplification with the nine and ten primer sets of p73 and p21 promoter respectively. (A) AR immunoprecipitated fraction was subjected to PCR amplification with the nine primers sets of $\mathrm{p} 73$ promoter. Amplification was observed with primer sets 8 (lane 8 ) in vehicle-treated controls and primer sets 2 and 8 (lane $2,8)$ after DHT treatment. (B) AR immunoprecipitated fraction was subjected to PCR amplification with the ten primers sets of $\mathrm{p} 21$ promoter. Amplification

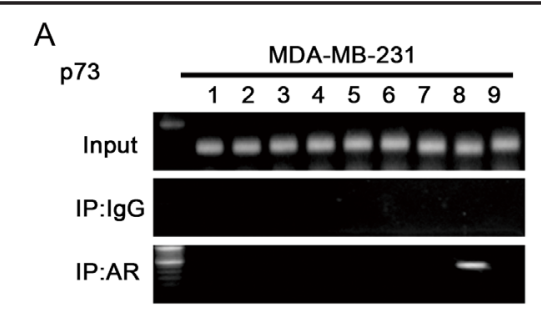

B

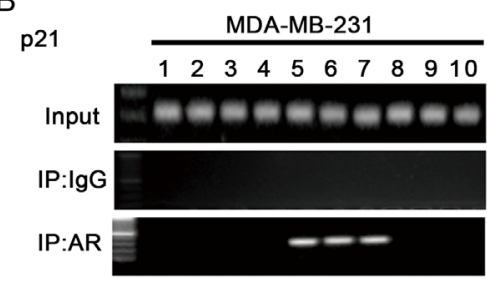

C

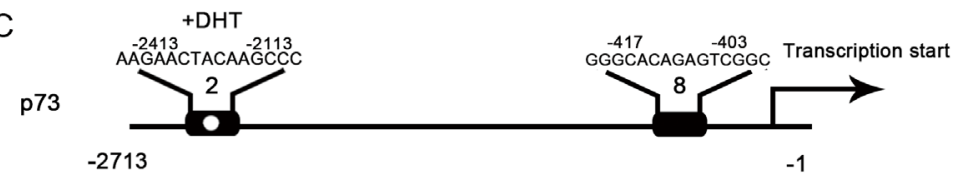

p21

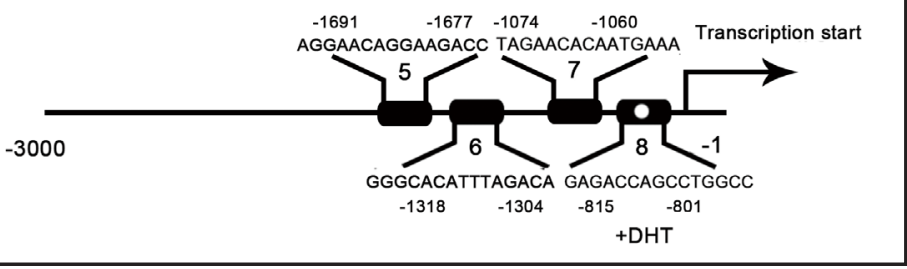
was observed with primer sets 5, 6 and 7 (lane 5,6,7) in vehicle-treated controls, and primer sets 5, 6, 7 and 8 (lane 5, 6, 7, 8) after DHT treatment. (C) A schematic model of AR binding sites in p73 promoter and p21 promoters. The sites and sequences of the binding sites were indicated in model.

AR to 73 promoter located at -613 to -313 bp upstream of transcription start site. Similarly, our results revealed that $A R$ can bind to the region of p21 promoter located at -1800 to $-900 \mathrm{bp}$ upstream of transcription start site (Fig. 4B, lane 5, 6, 7), which contains at least 3 binding sites. We observed that AR was able to bind to the region of p73 promoter located at -300 to -600 bp (Fig. 4A, lane 2) and p21 promoter located at -900 to -600 bp (Fig. 4B, lane 8) after DHT treatment respectively. Our results indicated that DHT-activated AR enhanced the regulation of AR on the transcription of p73 and p21. Furthermore, the putative binding sites of AR to p73 and p21 promoters were predicted by bioinformatic analysis, and most of binding sites are consistent with our results. Therefore, according to the results of bioinformatic analysis and ChIP assay, we proposed the model (Fig. 4C) which indicated the sites and sequences of the binding regions for AR. In brief, our results suggested that AR is able to specifically bind to the region of both p73 and p21 promoters, suggesting that AR regulated the expression of p73 and p21 through directly binding to their promoters. DHT administration promoted this procedure and make the binding more effectively.

\section{Bicalutamide inhibits tumor growth in xenograft}

In order to explore the effect of AR in MSL TNBC in vivo, we used BALB/c mice to establish an AR-positive TNBC subcutaneous transplantation tumor model with MDA-MB-231 cells. After tumor reached $100 \mathrm{~mm}^{3}$, the mice were received DHT or bicalutamide treatment. After 4 weeks of treatment, DHT dramatically promoted the growth of MDA-MB-231 tumor in vivo while bicalutamide treatment resulted in the inhibition of tumor growth (Fig. 5C).

Tumor sections from each treatment were analyzed by IHC of AR and its targets. As showed in Fig. 5D, hemotoxylin and eosin (H\&E) staining of paraffin-embedded tumor 


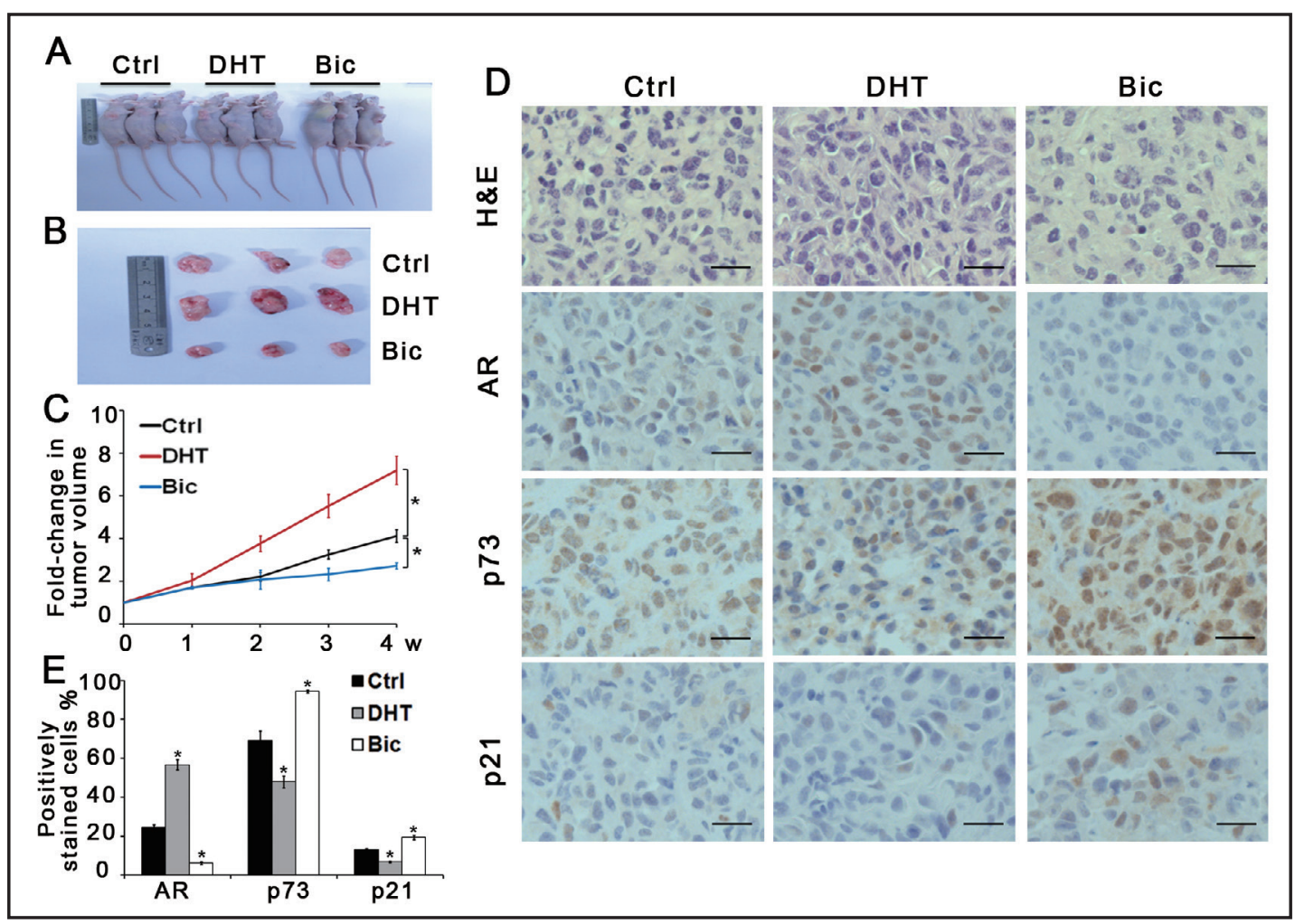

Fig. 5. Effects of DHT and bicalutamide on MDA-MB-231 tumors in vivo. (A, B) Representative image of xenograft tumors after treatments of DHT, bicalutamide or untreated. (C) Fold change in tumor volume is shown for each in vivo treatment group. (D) The tumor sections were subjected to histological analysis by H\&E staining and IHC staining of indicated proteins. Photomicrographs depict representative AR, p73, p21 staining (400×). Scale bars represent $50 \mu \mathrm{m}$. (E) AR, p73, p21 protein expression in MDA-MB-231 xenografts were quantified in IHC. $* P<0.05, * * P<0.01$.

sections demonstrated that bicalutamide decreased tumor cell density compared to vehicletreated controls. The level of AR, p73 and p21 were assessed by IHC on the harvested xenograft tumors. The results were then compared between different in vivo therapy groups. IHC staining revealed that the tumor cells expressed low levels of nuclear AR, while DHTtreated group showed significant increase in nuclear AR to 2.5 fold, and decrease in p73 and p21 levels compared to tumor from group without DHT treatment (Fig. 5D). Moreover, treatment of bicalutamide led to significant reduction of nuclear AR and elevated p73 and p21 nuclear staining in tumors. Collectively, DHT promotes the TNBC tumor growth through decreasing p73 and p21 levels, while bicalutamide elevated the p73 and p21 expression, resulting in reduction of tumor volume (Fig. 5D), which was consistent with findings in vitro. These results indicate that AR regulation of p73 and p21 is one mechanism by which AR effects proliferation and apoptosis in MSL TNBC with AR expression.

\section{Discussion}

Steroid hormone receptors like ER $\alpha$, PR and HER-2 are not expressed in TNBC, resulting in traditional endocrine therapies for TNBC are not effective compared with other subtypes of breast cancer. As we know, AR is a member of the steroid hormone receptor family, expresses in up to one-third of TNBC tumors [5-8]. Therefore, if AR is an effective target in AR-positive TNBC, patients with AR expression could benefit from AR-targeted therapy. Emerging evidences have demonstrated that AR serves as an oncogenic factor in AR+/ERbreast cancer [21-23], AR inhibition reduces survival and growth in these breast cancer 


\section{Cellular Physiology Cell Physiol Biochem 2016;38:1003-1014 \\ \begin{tabular}{ll|l} 
and BiOChemistry & $\begin{array}{l}\text { DOI: 10.1159/000443052 } \\
\text { Published online: March 04, } 2016\end{array}$ & $\begin{array}{l}\text { C } 2016 \text { The Author(s). Published by S. Karger AG, Basel } \\
\text { www.karger.com/cpb }\end{array}$
\end{tabular} \\ Zhu et al.: Targeting Androgen Receptor in Triple-Negative Breast Cancer}

cells [23]. In addition, anti-tumor effect of AR inhibition was also demonstrated in TNBC cells. A new generation of AR inhibition, enzalutamine, generally used in castration-resistant prostate cancer [24], is able to decrease proliferation and induces apoptosis in TNBC cell lines [25]. Furthermore, we have investigated the tumourgenesis role of AR and correlation between AR and cell cycle related genes in MSL TNBC which expresses relative lower AR compared with LAR TNBC. Consistent with previous observations [10], we detected that activated AR increases cell viability and reduced apoptosis in two AR-positive MSL TNBC cell lines. Pharmacological inhibition of AR with bicalutamide inhibits cell proliferation in a dose-dependent way. We also found that AR antagonist treatment causes early apoptosis.

As a ligand-dependent transcription factor, AR affects cancer cell growth, as well as regulates multiple genes expression. To better investigate the role of androgen-activated AR in TNBC, we assessed cell cycle related genes upon AR agonist and antagonist. AR regulation of cell cycle related genes may be one mechanism by which AR mediates breast cancer cells survival. As we know, p53 is classical tumor suppressor, and low level of p53 present in proliferation cancer cells. In previous studies, we found that p53 is mutated in multiple breast cancer cell lines, including MSL TNBC, which also occurs in MDA-MB-231 and Hs578T cell lines, as MDA-MB-231 cell contains a point mutation in the endogenous p53 gene [15, 26]. A mutant $p 53$ could inverse the function as tumor suppressor as wild type p53 in cancer cell, associated with cell migration and invasion in vitro $[27,28]$. Interestingly, we observed a significant increase of p53 level after DHT treatments. Therefore, we propose that DHTactivated may elevate expression of mutant p53 but not wild type p53, and DHT-activated AR promotes breast cancer cell proliferation and decreasing apoptosis through accumulation of mutant p53. As the member of p53 family [29], unlike p53, p73 is rarely mutant or lost in cancers [30]. Cyclin-dependent kinase p21 is tumor suppressor, which promotes cell cycle arrest, blocks cell division, and down-regulation of p21 often occurs in breast cancer [31]. Recent studies have demonstrated that $\mathrm{p} 21$ involved in anti-tumor progression in breast cancer, and anti-tumor drug increased p21 expression which led to breast cancer cell apoptosis [32,33]. p73 and p21 can promote anti-proliferation activity and induce apoptosis by p53-independent mechanisms [34, 35]. This inhibitory effect of AR is observed at the level of p73 and p21, detected a reduction in protein level following DHT treatment. In addition, AR inhibition results in the up-regulation of $\mathrm{p} 73$ and p21 both in vitro and in vivo xenograft model, while DHT decreases levels of p73 and p21, leading to the reduction of tumor volume.

Since AR plays a major role in decreasing Cyclin D1 expression and interacting with the ARE containing region of the Cyclin D1 promoter [20], we wished to explore whether AR also acts inhibitor of Cyclin D1 in AR-positive TNBC. Interestingly, we find that DHT positively regulates Cyclin D1 in protein level, not consistent in ER-positive breast cancer cell (MCF-7), as DHT leads to the reduction of Cyclin D1 in both protein and RNA levels and decrease of its promoter activity [20]. It is possible that AR signaling inhibits cell proliferation and exerts as tumor suppressor in ER+/AR+ breast cancer. The discrepancy in results may be due to the difference in ER status of breast cancer, as AR can bind to sites normally occupied by ER in a breast cancer [21]. Whether AR or androgen regulates breast cancer cells proliferation depends on tumor ER status needs further investigation.

$\mathrm{AR}$ is the member of the nuclear receptor family of ligand-induced transcription factors, which can influence the expression of target genes by binding to the specific or non-specific regions, including PSA promoter [36, 37]. As AR acts as transcription factor, we designed to determine whether AR interacts with the region of $\mathrm{p} 73$ or $\mathrm{p} 21$ promoters. The interaction between AR and the p73, p21 promoters is supported by ChIP analysis showing that AR occupancy of the promoter region, which is consistent with the results of bioinformatic analysis. The transcription of p73 and p 21 are negatively modulated through direct binding of AR to their promoters. Furthermore, AR is able to bind to the specific regions of p73 and p21 promoters after AR agonist DHT treatment, as shown in Fig. 4A (lane 2) and Fig. 4B (lane 8). We consider that AR occupies the promoter region of $\mathrm{p} 73$ and $\mathrm{p} 21$, so that the positive regulators of $\mathrm{p} 73$ and $\mathrm{p} 21$ could not bind to the promoters, which led to the down-regulation of p73 and p21. Furthermore, DHT enhance the inhibitory of AR on the transcription of 


\section{Cellular Physiology Cell Physiol Biochem 2016;38:1003-1014 \begin{tabular}{l|l} 
and Biochemistry Published online: March 04, 2016 & $\begin{array}{l}\text { C } 2016 \text { The Author(s). Published by S. Karger AG, Basel } \\
\text { www.karger.com/cpb }\end{array}$
\end{tabular} \\ Zhu et al.: Targeting Androgen Receptor in Triple-Negative Breast Cancer}

p73 and p21. In brief, we propose that the negative modulation of AR on p73 and p21 through directly binding to the promoters, and DHT-activated AR is able to promote these processes. It might also contribute to explain the positive influence of androgens on TNBC cell proliferation. Collectively, our data suggests that activated AR promotes cell proliferation via regulating p53, p73, p21 and Cyclin D1. In contrast, AR inhibition could inverse the function of androgen, serves as
Fig. 6. A schematic model of the regulatory role of AR in altering TNBC cell proliferation and apoptosis.

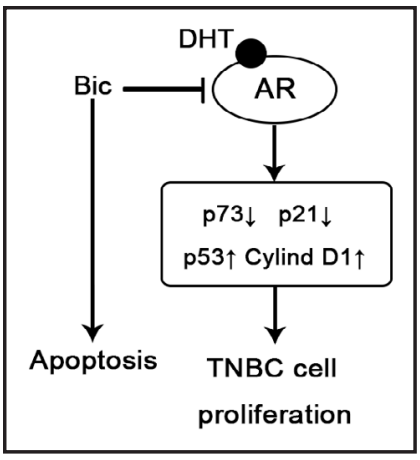

tumor suppressor in AR-positive TNBC. Therefore, we hypothesize that targeting AR could be an opportunity for AR-positive TNBC.

Preclinical studies and clinical trials have demonstrated that androgens can induce proliferative changes in breast cancer cells and promote tumorigenesis in xenograft by AR. In previous studies, AR inhibition enzalutamide decreases SUM159PT tumor viability in vivo, causes median $90 \%$ of necrotic tumor compared with $10 \%$ in untreated group and TUNEL staining. Recent study has suggested that xenograft tumors derived from different TNBC cell lines display different sensitivity to bicalutamide, suggesting that tumor derived from TNBC cell lines display significantly sensitivity to AR inhibition [10]. In our study, decreased viability by AR inhibition in vitro was reduplicated in MDA-MB-231 xenografts in nude mice, as AR inhibition results in decrease of tumor volume compared with vehicletreated controls. In brief, our data of preclinical studies indicates that targeting AR with antagonist such as bicalutamide could be a promising way for AR-positive TNBC treatments. In recent years, $A R$ is receiving increased attention as a therapeutic target in AR-positive breast cancers, as various clinical studies have focused on the functional role of AR in breast cancer. AR is currently being tested in TNBC, in which AR is regarded to be associated with worse clinical outcome in TNBCs [38]. Safety and efficacy of AR antagonist bicalutamide, enzalutamide and abiraterone acetase have been analyzed in recent clinical trials. Phase II clinical trial of anti-androgen with bicalutamide for ER-/PR-/AR+ metastatic breast cancer reports a 19\% clinical benefit and 12 weeks longer median progression-free survival [11]. Furthermore, the anti-tumor activity of a new generation anti-androgen abiraterone acetase in patients with HER-2 negative molecular apocrine breast cancer is assessed in an ongoing clinical trial (NCT01842321). An underway trial is designed to study the efficacy of PIK3CA inhibition taselisib and AR inhibition enzalutamide in treating patients with AR-positive metastatic TNBC (NCT02457910). In addition, our team has focused on the efficacy of the treatment of patients with AR-positive metastatic TNBC (NCT02353988), which is ready for recruitment. Overall, our data support a therapeutic benefit for the therapy with AR inhibition bicalutamide in MSL TNBC which expresses relatively low AR expression both in vivo and in vitro. The clinical trial recruited TNBC patients with AR expression $(>1 \%)$ assessed by IHC, and now 118 patients are eligible for treatment (NCT01889238). Furthermore, we provided a possible model of AR in TNBC which was presented in Fig. 6.

In summary, impairing androgen receptor signaling with bicalutamide inhibits cell proliferation and induces apoptosis in MSL TNBC cell lines in vitro via increasing the expression of p73 and p21 and negatively regulating p53 and Cyclin D1. Moreover, AR modulates the expression of both $\mathrm{p} 21$ and p73 via directly binding to the promoters, indicating that p73 and p21 are the downstream target genes of AR. Treatment of bicalutamide significantly decreases tumor volume in xenograft with MDA-MB-231. Our studies provide a novel insight of AR which functions as an oncogene in TNBC and it may be a therapeutic opportunity for patients with AR-positive TNBC tumor. However, further studies and mechanistic investigations of the regulation of androgen and AR in TNBC are needed. 


\section{Cellular Physiology Cell Physiol Biochem 2016;38:1003-1014

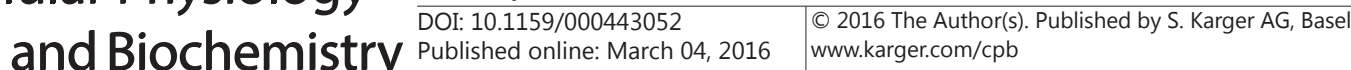 \\ Zhu et al.: Targeting Androgen Receptor in Triple-Negative Breast Cancer}

\section{Acknowledgements}

This work was supported by National Natural Science Foundation of China (No.81470357), and a Foundation for Clinical Medicine Science and Technology Special Project of the Jiangsu Province, China (No. BL2014071) (to X. G).

\section{Disclosure Statement}

Authors declare that they have no competing interests.

\section{References}

1 Dent R, Trudeau M, Pritchard KI, Hanna WM, Kahn HK, Sawka CA, Lickley LA, Rawlinson E, Sun P, Narod SA: Triple-negative breast cancer: clinical features and patterns of recurrence. Clin Cancer Res 2007;13:44294434.

2 Haffty BG, Yang Q, Reiss M, Kearney T, Higgins SA, Weidhaas J, Harris L, Hait W, Toppmeyer D: Locoregional relapse and distant metastasis in conservatively managed triple negative early-stage breast cancer. J Clin Oncol 2006;24:5652-5657.

3 Skor MN, Wonder EL, Kocherginsky M, Goyal A, Hall BA, Cai Y, Conzen SD: Glucocorticoid receptor antagonism as a novel therapy for triple-negative breast cancer. Clin Cancer Res 2013;19:6163-6172.

$4 \quad$ Lonergan PE, Tindall DJ: Androgen receptor signaling in prostate cancer development and progression. J Carcinog 2011;10:20.

5 Collins LC, Cole KS, Marotti JD, Hu R, Schnitt SJ, Tamimi RM: Androgen receptor expression in breast cancer in relation to molecular phenotype: results from the Nurses' Health Study. Mod Pathol 2011;24:924-931.

6 Mrklic I, Pogorelic Z, Capkun V, Tomic S: Expression of androgen receptors in triple negative breast carcinomas. Acta Histochem 2013;115:344-348.

7 Thike AA, Yong-Zheng Chong L, Cheok PY, Li HH, Wai-Cheong Yip G, Huat Bay B, Tse GM, Iqbal J, Tan PH: Loss of androgen receptor expression predicts early recurrence in triple-negative and basal-like breast cancer. Mod Pathol 2014;27:352-360.

8 Safarpour D, Pakneshan S, Tavassoli FA: Androgen receptor (AR) expression in 400 breast carcinomas: is routine AR assessment justified? Am J Cancer Res 2014;4:353-368.

9 Peters AA, Buchanan G, Ricciardelli C, Bianco-Miotto T, Centenera MM, Harris JM, Jindal S, Segara D, Jia L, Moore NL, Henshall SM, Birrell SN, Coetzee GA, Sutherland RL, Butler LM, Tilley WD: Androgen receptor inhibits estrogen receptor-alpha activity and is prognostic in breast cancer. Cancer Res 2009;69:61316140.

10 Lehmann BD, Bauer JA, Chen X, Sanders ME, Chakravarthy AB, Shyr Y, Pietenpol JA: Identification of human triple-negative breast cancer subtypes and preclinical models for selection of targeted therapies. J Clin Invest 2011;121:2750-2767.

11 Gucalp A, Tolaney S, Isakoff SJ, Ingle JN, Liu MC, Carey LA, Blackwell K, Rugo H, Nabell L, Forero A, Stearns V, Doane AS, Danso M, Moynahan ME, Momen LF, Gonzalez JM, Akhtar A, Giri DD, Patil S, Feigin KN, Hudis CA, Traina TA, Translational Breast Cancer Research C: Phase II trial of bicalutamide in patients with androgen receptor-positive, estrogen receptor-negative metastatic Breast Cancer. Clin Cancer Res 2013;19:55055512.

12 Arce-Salinas C, Riesco-Martinez MC, Hanna W, Bedard P, Warner E: Complete Response of Metastatic Androgen Receptor-Positive Breast Cancer to Bicalutamide: Case Report and Review of the Literature. J Clin Oncol 2014;10.1200/JCO.2013.49.8899

13 Fang Z, Zhang T, Dizeyi N, Chen S, Wang H, Swanson KD, Cai C, Balk SP, Yuan X: Androgen Receptor Enhances p27 Degradation in Prostate Cancer Cells through Rapid and Selective TORC2 Activation. J Biol Chem 2012;287:2090-2098.

14 Xu Y, Chen SY, Ross KN, Balk SP: Androgens induce prostate cancer cell proliferation through mammalian target of rapamycin activation and post-transcriptional increases in cyclin D proteins. Cancer Res 2006;66:7783-7792.

15 Neve RM, Chin K, Fridlyand J, Yeh J, Baehner FL, Fevr T, Clark L, Bayani N, Coppe JP, Tong F, Speed T, Spellman PT, DeVries S, Lapuk A, Wang NJ, Kuo WL, Stilwell JL, Pinkel D, Albertson DG, Waldman FM, McCormick F, Dickson RB, Johnson MD, Lippman M, Ethier S, Gazdar A, Gray JW: A collection of breast cancer cell lines for the study of functionally distinct cancer subtypes. Cancer Cell 2006;10:515-527. 


\section{Cellular Physiology Cell Physiol Biochem 2016;38:1003-1014

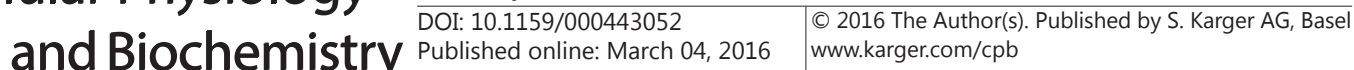 \\ Zhu et al.: Targeting Androgen Receptor in Triple-Negative Breast Cancer}

16 Kastan MB, Berkovich E: p53: a two-faced cancer gene. Nat Cell Biol 2007;9:489-491.

17 Arnold A, Papanikolaou A: Cyclin D1 in breast cancer pathogenesis. J Clin Oncol 2005;23:4215-4224.

18 Gillett C, Fantl V, Smith R, Fisher C, Bartek J, Dickson C, Barnes D, Peters G: Amplification and overexpression of cyclin D1 in breast cancer detected by immunohistochemical staining. Cancer Res 1994;54:1812-1817.

19 Buckley MF, Sweeney KJ, Hamilton JA, Sini RL, Manning DL, Nicholson RI, deFazio A, Watts CK, Musgrove EA, Sutherland RL: Expression and amplification of cyclin genes in human breast cancer. Oncogene 1993;8:2127-2133.

20 Lanzino M, Sisci D, Morelli C, Garofalo C, Catalano S, Casaburi I, Capparelli C, Giordano C, Giordano F, Maggiolini M, Ando S: Inhibition of cyclin D1 expression by androgen receptor in breast cancer cells-identification of a novel androgen response element. Nucleic Acids Res 2010;38:5351-5365.

21 Ni M, Chen Y, Lim E, Wimberly H, Bailey ST, Imai Y, Rimm DL, Liu XS, Brown M: Targeting androgen receptor in estrogen receptor-negative breast cancer. Cancer Cell 2011;20:119-131.

22 Naderi A, Hughes-Davies L: A functionally significant cross-talk between androgen receptor and ErbB2 pathways in estrogen receptor negative breast cancer. Neoplasia 2008;10:542-548.

23 Naderi A, Chia KM, Liu J: Synergy between inhibitors of androgen receptor and MEK has therapeutic implications in estrogen receptor-negative breast cancer. Breast Cancer Res 2011;13:R36.

24 Scher HI, Fizazi K, Saad F, Taplin ME, Sternberg CN, Miller K, de Wit R, Mulders P, Chi KN, Shore ND, Armstrong AJ, Flaig TW, Flechon A, Mainwaring P, Fleming M, Hainsworth JD, Hirmand M, Selby B, Seely L, de Bono JS, Investigators A: Increased survival with enzalutamide in prostate cancer after chemotherapy. $\mathrm{N}$ Engl J Med 2012;367:1187-1197.

25 Barton VN, D'Amato NC, Gordon MA, Lind HT, Spoelstra NS, Babbs BL, Heinz RE, Elias A, Jedlicka P, Jacobsen BM, Richer JK: Multiple molecular subtypes of triple-negative breast cancer critically rely on androgen receptor and respond to enzalutamide in vivo. Mol Cancer Ther 2015;14:769-778.

26 O'Connor PM, Jackman J, Bae I, Myers TG, Fan S, Mutoh M, Scudiero DA, Monks A, Sausville EA, Weinstein JN, Friend S, Fornace AJ, Jr., Kohn KW: Characterization of the p53 tumor suppressor pathway in cell lines of the National Cancer Institute anticancer drug screen and correlations with the growth-inhibitory potency of 123 anticancer agents. Cancer Res 1997;57:4285-4300.

27 Olive KP, Tuveson DA, Ruhe ZC, Yin B, Willis NA, Bronson RT, Crowley D, Jacks T: Mutant p53 gain of function in two mouse models of Li-Fraumeni syndrome. Cell 2004;119:847-860.

28 Lang GA, Iwakuma T, Suh YA, Liu G, Rao VA, Parant JM, Valentin-Vega YA, Terzian T, Caldwell LC, Strong LC, El-Naggar AK, Lozano G: Gain of function of a p53 hot spot mutation in a mouse model of Li-Fraumeni syndrome. Cell 2004;119:861-872.

29 Jost CA, Marin MC, Kaelin WG, Jr.: p73 is a simian [correction of human] p53-related protein that can induce apoptosis. Nature 1997;389:191-194.

30 Ozaki T, Nakagawara A: p73, a sophisticated p53 family member in the cancer world. Cancer Sci 2005;96:729-737.

31 Bachman KE, Blair BG, Brenner K, Bardelli A, Arena S, Zhou S, Hicks J, De Marzo AM, Argani P, Park BH: p21(WAF1/CIP1) mediates the growth response to TGF-beta in human epithelial cells. Cancer Biol Ther 2004;3:221-225.

32 Zhao S, Han J, Zheng L, Yang Z, Zhao L, Lv Y: MicroRNA-203 Regulates Growth and Metastasis of Breast Cancer. Cell Physiol Biochem 2015;37:35-42.

33 Karimian H, Fadaeinasab M, Moghadamtousi SZ, Hajrezaei M, Zahedifard M, Razavi M, Safi SZ, Mohan S, Khalifa SA, El-Seedi HR, Abdulla MA, Ali HM, Noordin MI: The Chemopreventive Effect of Tanacetum Polycephalum Against LA7-Induced Breast Cancer in Rats and the Apoptotic Effect of a Cytotoxic Sesquiterpene Lactone in MCF7 Cells: A Bioassay-Guided Approach. Cell Physiol Biochem 2015;36:9881003.

34 Abbas T, Dutta A: p21 in cancer: intricate networks and multiple activities. Nat Rev Cancer 2009;9:400414.

35 Hastak K, Alli E, Ford JM: Synergistic chemosensitivity of triple-negative breast cancer cell lines to poly(ADP-Ribose) polymerase inhibition, gemcitabine, and cisplatin. Cancer Res 2010;70:7970-7980.

36 Shan JD, Porvari K, Ruokonen M, Karhu A, Launonen V, Hedberg P, Oikarinen J, Vihko P: Steroid-involved transcriptional regulation of human genes encoding prostatic acid phosphatase, prostate-specific antigen, and prostate-specific glandular kallikrein. Endocrinology 1997;138:3764-3770.

37 Verrijdt G, Haelens A, Claessens F: Selective DNA recognition by the androgen receptor as a mechanism for hormone-specific regulation of gene expression. Mol Genet Metab 2003;78:175-185.

38 Choi JE, Kang SH, Lee SJ, Bae YK: Androgen receptor expression predicts decreased survival in early stage triple-negative breast cancer. Ann Surg Oncol 2015;22:82-89. 